\title{
Wpływ obróbki cieplnej na mikrostrukturę i odporność korozyjną bimetalu stal 904L - nikiel N02201 wytworzonego zgrzewaniem wybuchowym
}

\author{
Influence of heat treatment on microstructure \\ and corrosion resistance of the bimetal \\ steel 904L - nickel N02201 produced by explosive welding
}

\section{Streszczenie}

W artykule przedstawiono wyniki badań bimetalu 904L - N02201 połączonego metodą zgrzewania wybuchowego. Plater wykonano technologią zgrzewania wybuchowego, a następnie przeprowadzono wstępną obróbkę cieplną - wyżarzanie odprężające. Określono mikrostruktury złącza po wstępnej obróbce cieplnej, a zarazem w celu sprawdzenia odporności złącza na korozję, przeprowadzono dodatkową obróbkę cieplną. Kolejno, przy użyciu mikroskopu optycznego oraz skaningowego, wykonano badanie mikrostruktury po obróbce cieplnej. Przeprowadzono pomiary wielkości elektrycznych podczas korozji swobodnej w badaniach potencjodynamicznych, umożliwiające ocenę odporności na korozję.

Słowa kluczowe: zgrzewanie wybuchowe, obróbka cieplna, odporność korozyjna

\begin{abstract}
This paper presents the results research of bimetal $904 \mathrm{~L}-$ - N02201 connected using explosive welding method. Plater was performed using explosive welding technology, heat treatment was carried out pre-stress relief. The joint microstructure was defined after initial heat treatment and also to verify the corrosion resistance of the joint additional heat treatment was carried out. Consecutively, using an optical and scanning microscope, examination of the microstructure after heat treatment were performed. The electrical measurements were examined during free corrosion in the potentiodynamic studies enabling the evaluation of corrosion resistance.
\end{abstract}

Keywords: explosive welding, heat treatment, corrosion resistance

\section{Wstęp}

Zgrzewanie wybuchowe jest to proces technologiczny polegający na połączeniu dwóch lub więcej elementów metalowych za pomocą energii wyzwalającej się przy detonacji ładunku wybuchowego [1].

Uzyskane połączenia mogą mieć charakter adhezyjny, mechaniczny bądź dyfuzyjny. W przypadku połączeń mechaniczno - adhezyjnych otrzymane połączenie cechuje się wysoką jakością, natomiast połączenia dyfuzyjne powodują pogorszenie właściwości materiałów i odporności korozyjnej $[2,3]$. Wysokoenergetyczny proces łączenia wprowadza również do struktury wielowarstwowego materiału nie korzystne naprężenia i umocnienie, co negatywnie wpływa na właściwości użytkowe i ogranicza możliwości jego dalszego kształtowania metodami przeróbki plastycznej, czy obróbki ubytkowej [1]. W celu poprawy właściwości wytrzymałościowych normy PN-EN 13455-2 przewidują wykonanie obróbki cieplnej [4]. W przypadku kompozytów warstwowych wymagane jest, aby temperatura obróbki cieplnej była niższa od temperatury przejścia w stan ciekły warstwy złącza o najniższej temperaturze topnienia.

Analizowany w tym artykule bimetal ma znaleźć swoje zastosowanie jako materiał w przemyśle chemicznym i zbrojeniowym. Warunki pracy elementów wykonanych z opisywanego bimetalu wymagają szczelnego połączenia, wysokiej odporności na korozję, a także jak najlepszych właściwości mechanicznych, dlatego przeprowadzona została

Mgr inż. Urszula Sobczak - Wojskowa Akademia Techniczna Warszawa; mgr inż. Michał Najwer, mgr inż. Grzegorz Kwiatkowski - Politechnika Opolska, Zakład Technologii Wysokoenergetycznych EXPLOMET.

Autor korespondencyjny/Corresponding author. urszula.sobczak@wat.edu.pl 
obróbka cieplna mająca na celu usunięcie skutków zgniotu, uzyskanie odpowiedniej mikrostruktury oraz odporności na korozję [5]. W tym celu przeprowadzono analizę wpływu obróbki cieplnej na mikrostrukturę i właściwości mechaniczne plateru stal - stop niklu.

\section{Badania własne}

\section{Materiał do badań}

W ramach realizowanych badań wytworzono metodą zgrzewania wybuchowego bimetal, w którego skład wchodziła stal austenityczna 904L stanowiąca blachę podstawową o grubości $25 \mathrm{~mm}$ oraz stop niklu N02201 będący blachą nakładaną o grubości $6 \mathrm{~mm}$. Składy chemiczne łączonych materiałów zostały przedstawione w tablicach I i II. Wymiary końcowe łączonych blach wynosiły: $(25+6) \times 2000 \times 5000$.

Do analizy mikrostruktury oraz odporności na korozję materiał poddano początkowo wyżarzaniu odprężającemu w temperaturze $540{ }^{\circ} \mathrm{C}$ przez 90 min. Następnie badany materiał poddano dwuetapowej obróbce cieplnej. Etap pierwszy stanowiło przesycanie, próbki (1-4) o wymiarach (25+6) $\times 30 \times 20$ zostały wygrzane w temperaturze $1050^{\circ} \mathrm{C}$ przez $1 \mathrm{~h}$. Próbki chłodzone były w wodzie. Etap drugi stanowiło wygrzewanie próbek (2-4) w temperaturze $550^{\circ} \mathrm{C}$ przez 1 (próbka 2), 3 (próbka 3) oraz 5 (próbka 4) godzin. Próbki chłodzone były na powietrzu.

\section{Badanie mikrostruktury po obróbce cieplnej}

Zgłady metalograficzne trawiono dwuetapowo, najpierw wykonano trawienie stali austenitycznej odczynnikiem zawierającym $100 \mathrm{ml} \mathrm{H} 20+100 \mathrm{ml} \mathrm{HCl}+10 \mathrm{ml} \mathrm{HNO}_{3}$, który podgrzano do temperatury $50{ }^{\circ} \mathrm{C}$. Następnie wytrawiono nikiel odczynnikiem zawierającym $4 \mathrm{~g} \mathrm{CuSO}_{4}+20 \mathrm{ml} \mathrm{HCl}$ $+20 \mathrm{ml} \mathrm{C}_{2} \mathrm{H}_{5} \mathrm{OH}$. Mikrostruktury obserwowano na mikroskopie optycznym i skaningowym. Na rysunku 1 przedstawiono mikrostrukturę złącza platerowanego po przesycaniu w temperaturze $1050^{\circ} \mathrm{C}$ przez 1 godzinę.

$\mathrm{Na}$ rysunku 2 przedstawiono przykłady mikrostruktur ujawnionych na wytrawionym zgładzie metalograficznym w obszarze złącza oraz w materiałach zgrzewanych.

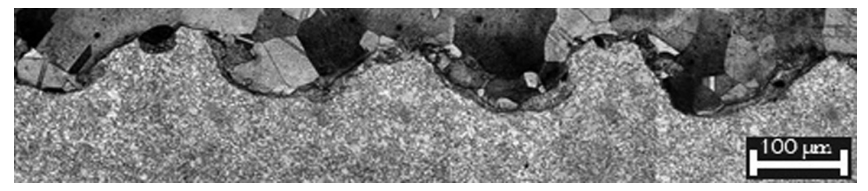

Rys. 1. Mikrostruktura złącza platerowanego

Fig. 1. The microstructure of the joint
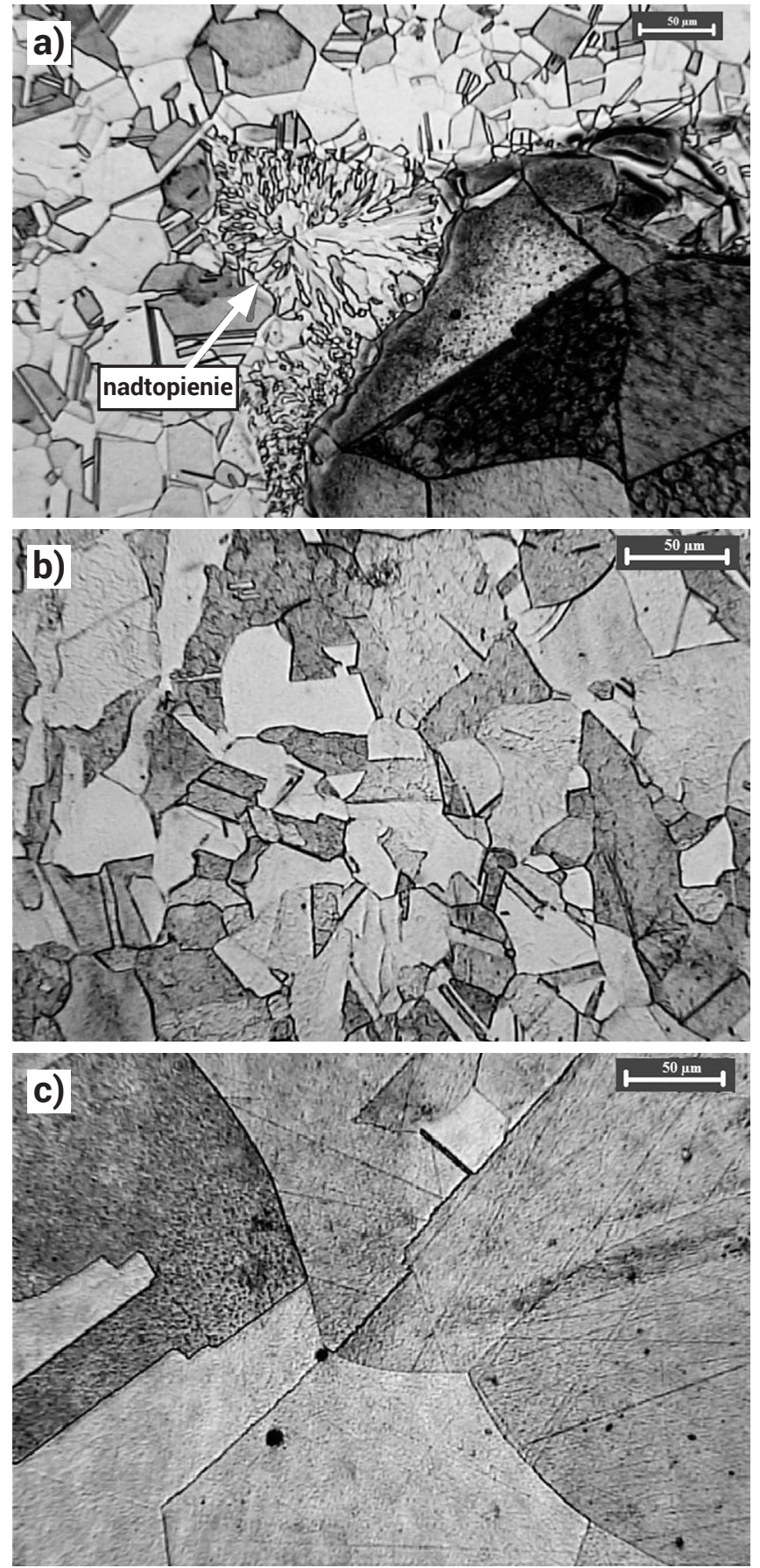

Rys. 2. Mikrostruktury próbki po przesycaniu $\left(1050^{\circ} / 1 \mathrm{~h} / \mathrm{H}_{2} \mathrm{O}\right)$ : a) obszar złącza, b) stal 904L, c) nikiel N02201

Fig. 2. Microstructure of the sample after annealing $\left(1050^{\circ} / 1 \mathrm{~h} / \mathrm{H}_{2} \mathrm{O}\right)$ : a) the area of joint, b) steel $904 \mathrm{~L}, \mathrm{c}$ ) nickel

Tablica I. Skład chemiczny badanej stali 904L [w \% wag.]

Table I. Chemical composition of investigated steel 904L [in \% wt.]

\begin{tabular}{|c|c|c|c|c|c|c|c|c|c|c|c|c|}
\hline $\mathbf{N r}$ & $\mathbf{S k ł a d}$ & $\mathbf{S}$ & $\mathbf{N i}$ & $\mathbf{M n}$ & $\mathbf{S i}$ & $\mathbf{T i}$ & $\mathbf{P}$ & $\mathbf{C r}$ & $\mathbf{C u}$ & $\mathbf{M o}$ & $\mathbf{N b}$ & $\mathbf{N}$ \\
\hline $904 \mathrm{~L}$ & 0,01 & 0,0005 & 24,235 & 1,535 & 0,1836 & 0,013 & 0,0162 & 19,69 & 1,3098 & 4,0054 & 0,008 & 0,057 \\
\hline
\end{tabular}

Tablica II. Skład chemiczny stopu niklu N02201 [w \% wag.]

Table II. Chemical composition of investigated nickel alloy N02201 [in \% wt.]

\begin{tabular}{|c|c|c|c|c|c|c|c|c|c|}
\hline $\mathbf{N r}$ & $\mathbf{S k ł a d}$ & $\mathbf{S}$ & $\mathbf{N i}$ & $\mathbf{M n}$ & $\mathbf{S i}$ & $\mathbf{T i}$ & $\mathbf{C u}$ & $\mathbf{F e}$ & $\mathbf{M g}$ \\
\hline $\mathrm{N} 02201$ & 0,01 & $<0,0002$ & 99,7 & 0,09 & 0,06 & 0,02 & $<0,01$ & 0,03 & 0,02 \\
\hline
\end{tabular}


Wielkość ziarna niklu (rys. 2c) jest wielokrotnie większa od wielkości ziarna stali 904L (rys. 2b). W obu materiałach występują bliźniaki wyżarzania. W niektórych obszarach obserwuje się efekty nadtopienia, charakteryzujące się budową drobnoziarnistą (rys. 2a).

\section{Analiza mikrostruktury za pomocą SEM}

Za pomocą programu komputerowego CarbNit i mikroskopu skaningowego Hitachi 3500 N, wykonano analizę termodynamiczną wydzieleń w zgrzewanym materiale. Podczas przeprowadzonej analizy węglikoazotków wykazano, że węgiel i azot nie został w całości związany (rys. 3). Zauważono, że zawartość węgla praktycznie się nie zmienia a wraz z obniżeniem temperatury maleje ilość azotu rozpuszczonego w stali.

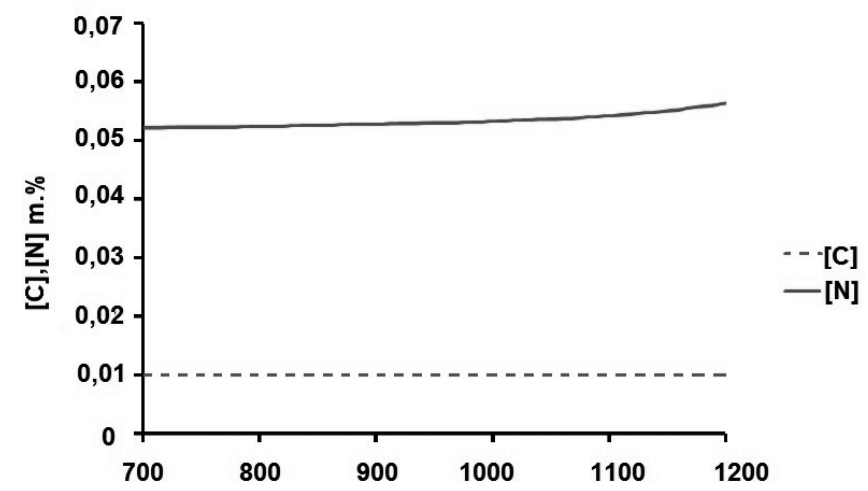

Rys. 3. Skład chemiczny austenitu

Fig. 3. Chemical composition of the austenite

Potwierdzeniem tych obliczeń są wydzielenia zaobserwowane w badanym materiale (rys. 4).
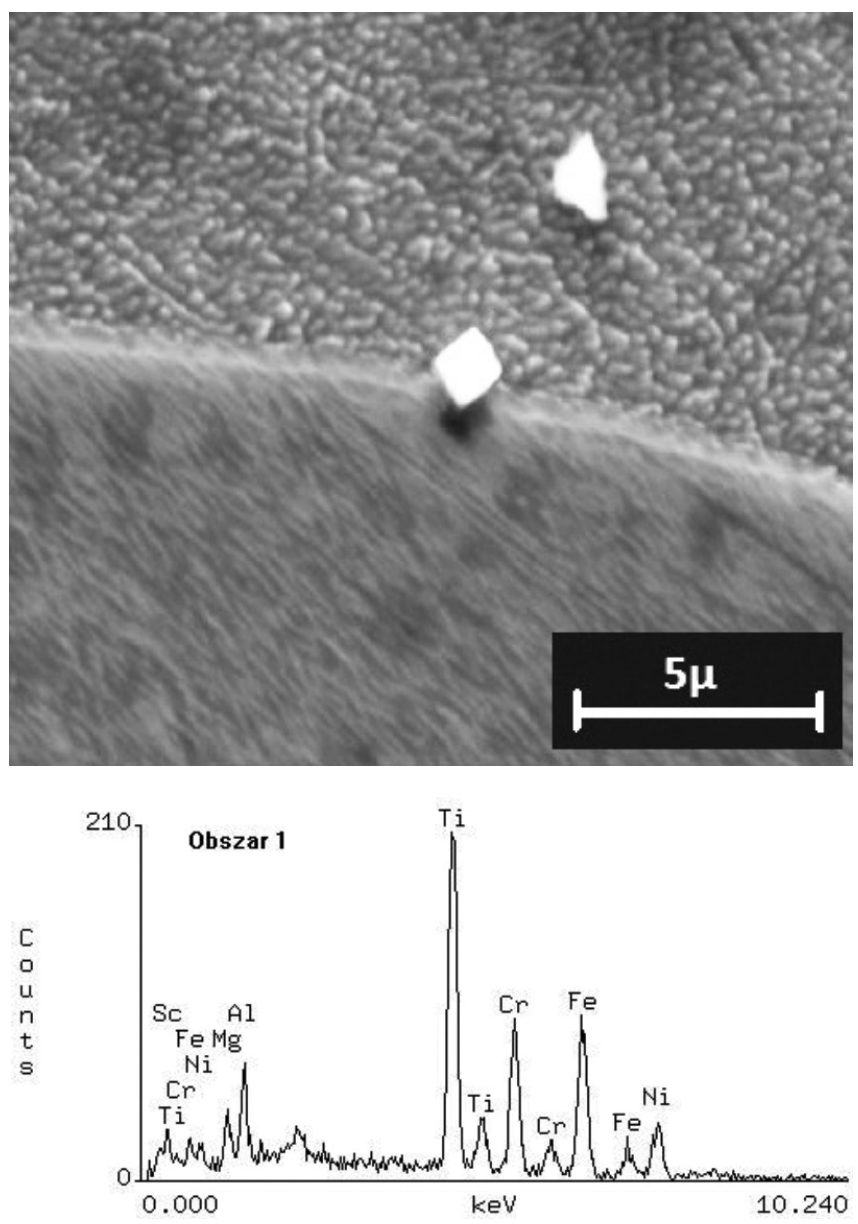

Wewnątrz ziarn stwierdzono występowanie azotków i węglików. Po wykonaniu analizy składu chemicznego stwierdzono, że są to azotki tytanu TiN (rys. 4a) oraz węgliki chromu $\mathrm{Cr}_{23} \mathrm{C}_{6}$ (rysunek $4 \mathrm{~b}$ ).

\section{Badania odporności na korozję}

Dla próbki 1 (linia przerywana) oraz 4 (linia ciągła) wykonano pomiar potencjału korozyjnego OCP (Open Circuit Potential). Jest to istotny parametr pozwalający na przewidywanie odporności korozyjnej badanego materiału metalicznego [7]. Badanie polegało na pomiarze potencjału bimetalu, w warunkach bezprądowych, względem elektrody odniesienia [8]. Na rysunku 5 przedstawiono zbiorczy wykres parametru OCP dla badanych materiałów. Próbki po przesycaniu (4) mają wyższy potencjał, świadczący o ich odporności korozyjnej.

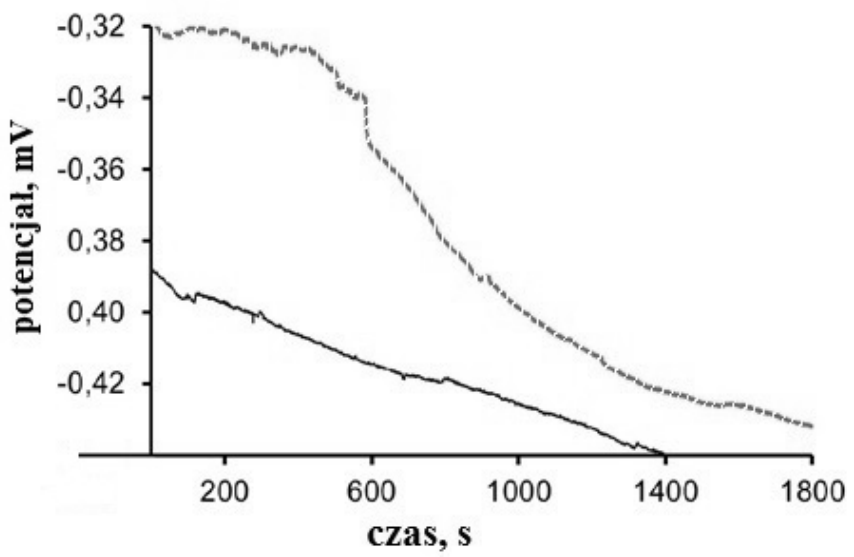

Rys. 5. Zbiorczy wykres parametru OCP

Fig. 5. Cumulative parameter graph of OCP
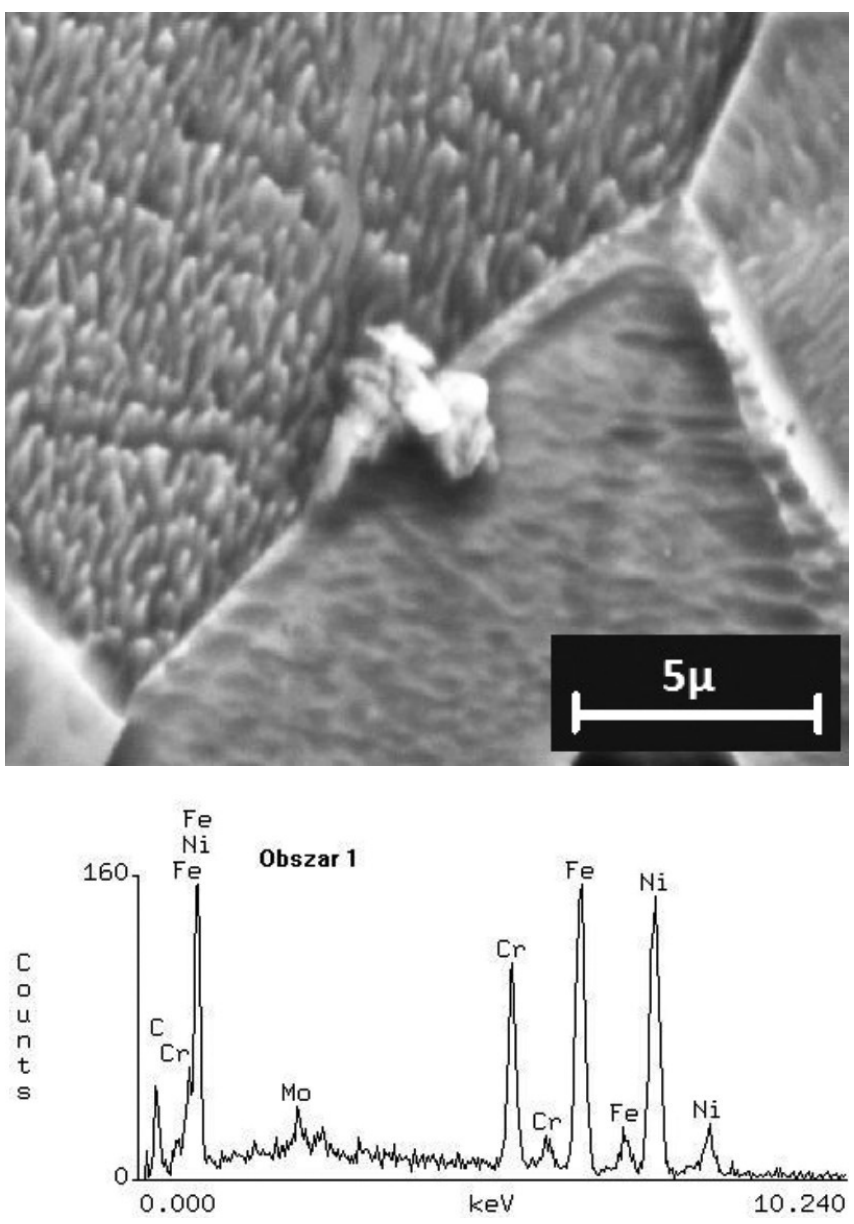

Rys. 4. Analiza mikrostruktury: a) wydzielenie azotku TiN w próbce po wyżarzaniu $550{ }^{\circ} \mathrm{C} / 5 \mathrm{~h}$, b) wydzielenie węglika $\mathrm{Cr}_{23} \mathrm{C}_{6} \mathrm{w}$ próbce po wyżarzaniu $550^{\circ} \mathrm{C} / 5 \mathrm{~h}$

Fig. 4. Analysis of the microstructure: a) eduction the nitride $\mathrm{TiN}$ in the sample after annealing $550{ }^{\circ} \mathrm{C} / 5 \mathrm{~h}, \mathrm{~b}$ ) eduction carbide $\mathrm{Cr}_{23} \mathrm{C}_{6}$ in the sample after annealing $550{ }^{\circ} \mathrm{C} / 5 \mathrm{~h}$ 
Aby ocenić zachowanie korozyjne badanego bimetalu, przeprowadzono pomiary liniowej woltamperometrii LSV (Linear Sweep Voltammetry). Schemat wyznaczania parametrów krzywej otrzymanej w wyniku pomiarów woltamperometrycznych został przedstawiony na rysunku 6 . Pomiar polegał na rejestrowaniu odpowiedzi prądowej w zależności od liniowo rosnącego potencjału, który zadany był na badanej próbce. Dzięki temu otrzymano krzywe polaryzacyjne.

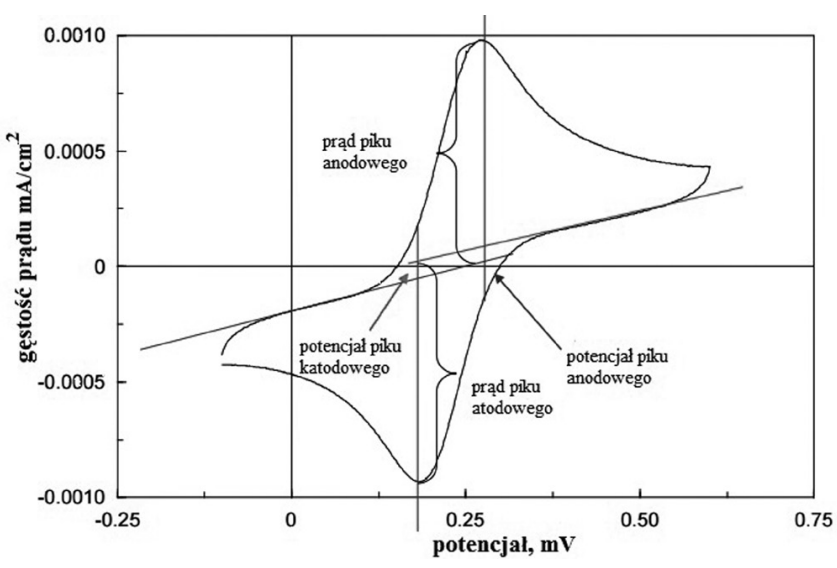

Rys. 6. Schemat wyznaczania parametrów LSV $[7,8]$

Fig. 6. Determining scheme parameters LSV $[7,8]$

Badania polaryzacyjne dla próbek przeprowadzono w 0,1M roztworze chlorku sodu, szybkość skanowania potencjału przeprowadzono dla pięciu wariantów: 16,6 mV/s, $50 \mathrm{mV} / \mathrm{s}, 83,3 \mathrm{mV} / \mathrm{s}, 166 \mathrm{mV} / \mathrm{s}, 332 \mathrm{mV} / \mathrm{s}$. Na rysunku 7 przedstawiono otrzymane krzywe polaryzacji katodowej i anodowej poprzez zastosowanie pomiaru potencjału bimetalu względem półogniwa kalomelowego w funkcji czasu przy stałej gęstości prądu. W celu otrzymania dokładnych wyników dla każdego pomiaru wykonano po trzy cykle. Odnosząc się do schematu zamieszczonego na rysunku 5 zauważono, że w materiale nie występuje korozja wżerowa. Największe potencjały wystąpiły dla pików wyznaczonych dla wariantu 16,6 mV/s. Ilość pików świadczy o ilości zachodzących reakcji. Dla każdej z badanych próbek występuje jeden pik prądu anodowego związany z reakcją utleniania.

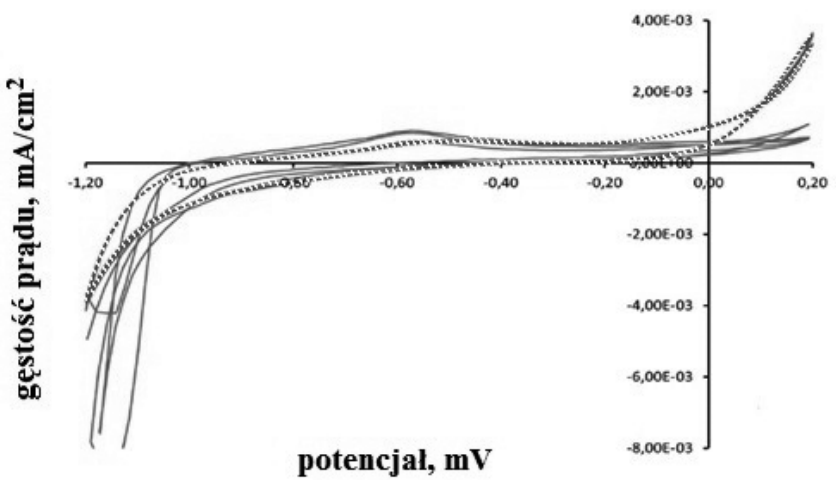

Rys. 7. Krzywe polaryzacji katodowej i anodowej dla potencjału $16,6 \mathrm{mV}$ Fig. 7. Polarization curves for the anodic and cathodic potential of $16,6 \mathrm{mV}$

Na powierzchnię stali austenitycznej jest nałożony nikiel, w związku z tym, reakcja jaka zachodzi, to utlenianie niklu zgodne z reakcją: $\mathrm{N}^{0}-2 \mathrm{e} \rightarrow \mathrm{N}^{2+}$. Ze wzrostem potencjału wzrasta wysokość piku, świadcząca o tym, że zachodząca reakcja jest szybka, potencjodynamiczna [8].

\section{Podsumowanie}

Plater, wykonany technologią zgrzewania wybuchowego poddano analizie wpływu obróbki cieplnej na jego mikrostrukturę i odporność korozyjną. Podczas przeprowadzonych badań zauważono, że wielkość ziaren stali austenitycznej różniła się kilkakrotnie od wielkości ziarna niklu, w linii złącza widoczne były obszary przetopione o drobnoziarnistej mikrostrukturze. Zarówno w mikrostrukturze stali austenitycznej, jak i niklu zaobserwowano bliźniaki wyżarzania. Na obrazach pochodzących z mikroskopu skaningowego zaobserwowano liczne wydzielenia takie jak: $\mathrm{TiN} \mathrm{Cr}_{23} \mathrm{C}_{6}$ oraz fazy międzymetaliczne molibdenu. Na podstawie obserwacji mikrostruktury wykonanej przy pomocy mikroskopu skaningowego i analizy termodynamicznej węglikoazotków stwierdzono, że tytan i niob, które powinny stabilizować austenit, nie spełniły swojej roli w badanym materiale. Zatem węgiel może w badanej stali wchodzić w relację z $\mathrm{Cr}$, co w środowisku korozyjnym może powodować korozję międzykrystaliczną. Jednak jego mała zawartość $(0,01 \%)$ nie powinna znacznie obniżać odporność stali na korozję. W dalszej części wykonano badanie odporności na korozję, a analiza parametru OCP wykazała, że próbki przesycone w temperaturze $1050{ }^{\circ} \mathrm{C}$ posiadają mniejszą tendencję do korozji w porównaniu z materiałem surowym. Otrzymane wyniki świadczą o tym, że pojawiająca się korozja ma charakter potencjodynamiczny i nie powinna wpływać znacząco na własności mechaniczne wykonanego plateru.

\section{Literatura}

[1] Najwer M., Niesłony P.: Ocena mikrotwardości oraz własności wytrzymałościowych trimetalu AA2519-AA1050-Ti6Al4V po różnych obróbkach cieplnych, Przegląd Spawalnictwa, nr 4, s. 16-18, 2016

[2] Kurek A.: Trwałość zmęczeniowa elementów maszyn wykonanych z bimetalu stal - tytan zgrzewanego wybuchowo, Politechnika Opolska, Opole, 2011

[3] Prażmowski M., Rozumek D., Paul H.: Trwałość zmęczeniowa bimetalu cyrkon-stal w aspekcie charakterystyki złącza, Przegląd Spawalnictwa, nr 4, s. 12-15, 2016

[4] Pocica A., Najwer M.: Obróbka cieplna zgrzewanych wybuchowo bimetali ze stali austenitycznych, Przegląd Spawalnictwa, nr 5, s. 54-58, 2014
[5] Schweitzer P.A.: Fundamentals of Corrosion - Mechanism, Causes and Preventative Methods, CRC Press, 2009

[6] Kozłowski J., Kozłowski J.: Spawanie to nie wszystko Zabezpieczenie antykorozyjne spawanych konstrukcji stalowych - kontrola i badania, Przegląd Spawalnictwa, nr 5, 10-15, 2016

[7] Adamiec J., Januszkiewicz M.: Ocena odporności na korozję wysokotemperaturową złączy spawanych laserowo rur ożebrowanych wykonanych ze stopów niklu, Przegląd Spawalnictwa, nr 10, 88-91, 2015

[8] Bard A.J., Inzelt G., Scholz F.: Electrochemical Dictionary Springer - Verlag, Berlin, Heidelberg, 2008. 